Short communication

\title{
INSECTICIDE SUSCEPTIBILITY OF HOUSE FLIES (MUSCA DOMESTICA) FROM A LIVESTOCK FARM IN TYUMEN REGION, RUSSIA
}

\author{
M. A. LEVCHENKO, E. A. SILIVANOVA, G. F. BALABANOVA \\ \& R. H. BIKINYAEVA
}

All-Russian Scientific Research Institute of Veterinary Entomology and Arachnology, Branch of Tyumen Scientific Centre, Siberian Branch of the Russian Academy of Sciences

\section{Summary}

Levchenko, M. A., E. A. Silivanova, G. F. Balabanova \& R. H. Bikinyaeva, 2019. Insecticide susceptibility of house flies (Musca domestica) from a livestock farm in Tyumen region, Russia. Bulg. J. Vet. Med., 22, No 2, 213-219.

The susceptibility of the field populations of the house fly Musca domestica L. (Diptera:Muscidae) from a livestock farm of the Tyumen region, Russia, to six insecticides (deltamethrin, cypermethrin, thiamethoxam, permethrin, fipronil, chlorfenapyr) is reported. After a forced contact of adult flies of susceptible strains and first generation of field populations with the residues of insecticides at the bottom of glass cups, the median lethal dose of each insecticide was determined by probit analysis. According to the resistance ratio, the susceptibility of the evaluated field population to insecticides increased in the order: cypermethrin $<$ deltamethrin $<$ permethrin $\leq$ chlorfenapyr $<$ thiamethoxam $<$ fipronil.

Key words: field population, insecticides, Musca domestica L., resistance ratio, susceptibility

The house fly Musca domestica L. (Diptera:Muscidae) is a typical representative of zoophilous flies that cause significant harm to the animals as ectoparasites and interfere with the work of the maintenance staff. Flies disturb the animals, reduce the sanitary condition of farms and animal feed, may be carriers of infectious and parasitic diseases of animals (Förster et al., 2007; Wang et al., 2011; Scott et al., 2014). The main method of house flies control worldwide is chemical control using insecticides. In Russia, pyrethroid and neonicotinoid insecticides are most commonly used to combat ectoparasites of animals. Fipronil and chlorfenapyr are among the new classes of insecticides in Russia. Fipronil is used in crop production, medical pest control (mainly in the form of gels and baits to control cockroaches), in veterinary medicine for combating ectoparasites on small domestic animals. Chlorfenapyr is a promising pyrrole insecticide to control the insect popu- 
lation. Chlorfenapyr, a pro-insecticide, has a unique mechanism of insecticidal activity connected to the ability of its metabolites to block the ATP synthesis in insect body cells (US EPA, 2001). In world practice, chlorfenapyr is mainly used in crop production and termite control, it is promising as a means to control the malaria vectors and other synanthrope insects (N'Guessan et al., 2007; Romero et al., 2010). It is not introduced widely in Russia and is mostly used for plant protection.

It is known that $M$. domestica quickly develops resistance to insecticides used against it (Scott et al., 2013; Khan et al., 2015). Previously, researchers reported on the formation of house fly populations resistant to pyrethroids and neonicotinoids on livestock and poultry farms around the world (Marçon et al., 2003; Kaufman et al., 2010; Khan et al., 2013; Scott et al., 2013; Abbas et al.. 2015). Development of cross-resistance to insecticides of other groups is also possible. For example, it is known that house fly population resistant to permethrin develops resistance to fipronil (Liu \& Yue, 2000).

Information on the susceptibility of $M$. domestica field populations to the insecticides used on the territory of Russia is sporadic and mainly refers to flies of towns (inhabited localities). Thus, in the 1990s, a study of 19 populations of flies from central (Moscow, Kaluga, Tver regions) and southern (Astrakhan) regions of Russia, demonstrated their high resistance to organophosphorus insecticides (chlorophos, carbofos) and tolerance or sensitivity to such pyrethroids as permethrin, neopinamine, fenvalerate (Polyakova, 1995). It has also been reported that the flies of the Moscow population were highly resistant to pyrethroids (Roslavtseva, 2001). Such studies of flies on livestock complexes are rare and have not been carried out for more than 10 years (Pavlov, 2006).

For effective control of the number of pests, including the housefly, it is necessary to carry out monitoring of the level of susceptibility in field populations to the used insecticides. The aim of this study was to assess the susceptibility to insecticides of different groups in the $M$. domestica population from a livestock farm in the Tyumen region, where pyrethroid insecticides had been used for a long time.

For the experiment, 3-5-day old laboratory susceptible and field populations adult flies were used. Field population of flies was collected in the facilities (piggeries, cowsheds) of a livestock farm in the Tyumen region (Chervishevo village, $56^{\circ} 56^{\prime} 08^{\prime \prime}$ N. $65^{\circ} 25^{\prime} 34^{\prime \prime}$ E.). Then insects were transferred in an insectarium and kept in cages made of metal frame $25 \times 25$ $\times 25 \mathrm{~cm}$ of size, covered with fine mesh, with a special sleeve to run insects. The cages also had food (milk powder: glucose 1:1) in Petri dishes and cups with water with a cotton wicks in them. The first generation of adult flies (F1) has been obtained in the laboratory out of the collected population of flies; it has been tested for susceptibility to insecticides. Susceptible insect culture was obtained from the laboratory of the Novosibirsk Agrarian University in 2009 and was reared in the insectarium without contact with insecticides for more than 50 generations.

The testing was carried out using commercial insecticides containing deltamethrin (Deltsid 4\% EC, Agrovetzashhita, Russia; FAS 1\% tablets, Agrovit on scientific and technological orders of Gigiena-Bio, Russia), cypermethrin (Samarovka insecticide 25\% EC, Samarovo, Russia), thiamethoxam (Agita 10\% WG, NOVARTIS ANIMAL HEALTH Inc., 
Switzerland), as well as industrial permethrin (97\%, crystals, China), fipronil (97\%, powder, China), chlorfenapyr (97\%, crystals, China).

To determine the toxicity of the insecticides for flies the method of dosed contacting of insects was used (Pavlov \& Pavlova, 2005). The insect groups were exposed to the test drug without anaesthetic by forced contact with an insecticide residues on the bottom of a glass cup for $30 \mathrm{~min}$. Acetone solutions of insecticide were prepared in 5-6 concentrations. Then, $1 \mathrm{~mL}$ of each solution was added to glass cups with diameter $35-40 \mathrm{~mm}$ and 40-45 mm height. After evaporation of acetone a certain amount of active substance - the dose - was left in each cup. Then 10 flies were placed into each cup by a piston, consisting of a mesh cloth and a spring spacer ring, achieving close contact of the insects with the insecticide residues on the bottom of a cup. After a 30-min exposure, pistons in cups were raised to supply insects with drinking bowls with $5 \%$ glucose solution. The death of the insects was registered during one day. Experiments with each dose of the insecticide were performed at least 3 times.

The results of insect mortality depending on the dose were analysed by probit analysis (Finney, 1971) using Free LD50/LC50 Calculator (July 7, 2016; Dr. M. Alpha Raj by Calcuating LD50/LC50 using Probit Analysis in Excel Blog) for calculating $\mathrm{LD}_{50}$ for $95 \%$ confidence intervals (CI), slopes, standard errors, and $\chi 2$. Median lethal dose was expressed as a microgram of the active substance per gram of tested insects' weight. To determine the susceptibility of the field population to the insecticides the resistance ratio (RR) was calculated as the ratio of $\mathrm{LD}_{50}$ of the insecticide for field population flies to $\mathrm{LD}_{50}$ for laboratory strain of flies. Susceptibility of the field population to the insecticides was determined based on the following criteria: $\mathrm{RR}<1$ - high susceptibility to the insecticide, $R R=1-$ absence of resistance (the population is sensitive to the insecticide), $R R=2-10$ - very low resistance (the insects are tolerant to the insecticide), $\mathrm{RR}=11-20$ - low resistance (the insects are moderately resistant), $\mathrm{RR}=21-50$ - medium resistance, $\mathrm{RR}=51-$ 100 - high resistance (the insects are resistant to the insecticide), RR $>100$ - very high resistance (the insects are highly resistant to the insecticide) (Dremova et al., 1999; Abbas et al., 2015).

Laboratory tests have shown that for flies of both laboratory and field populations the pyrethroid deltamethrin had the highest toxicity. Next came the pyrethroid cypermethrin, pyrazole fipronil and neonicotinoid thiamethoxam. The permethrin toxicity was significantly lower. The lowest toxicity against adults $M$. domestica of both laboratory and field populations was that of pyrrole chlorfenapyr (Table 1).

According to our results, the field populations of flies did not have a high resistance to deltamethrin, cypermethrin and permethrin. A very low resistance to cypermethrin $(\mathrm{RR}=3.66)$ and deltamethrin in the composition of the FAS preparation $(\mathrm{RR}=3.07)$ should be noted. A higher sensitivity to permethrin in the studied population of flies is probably due to the fact that insecticides containing this pyrethroid are quite rare.

House fly populations with varying degrees of resistance to pyrethroids were found around the world on livestock and poultry farms. For example, in the USA, Musca domestica caught in pens for cattle in the southeast Nebraska showed reasonable resistance to permethrin: resistance ratio of 7.3 when contacting with insecti- 
Insecticide susceptibility of house flies (Musca domestica) from a livestock farm in Tyumen region, Russia

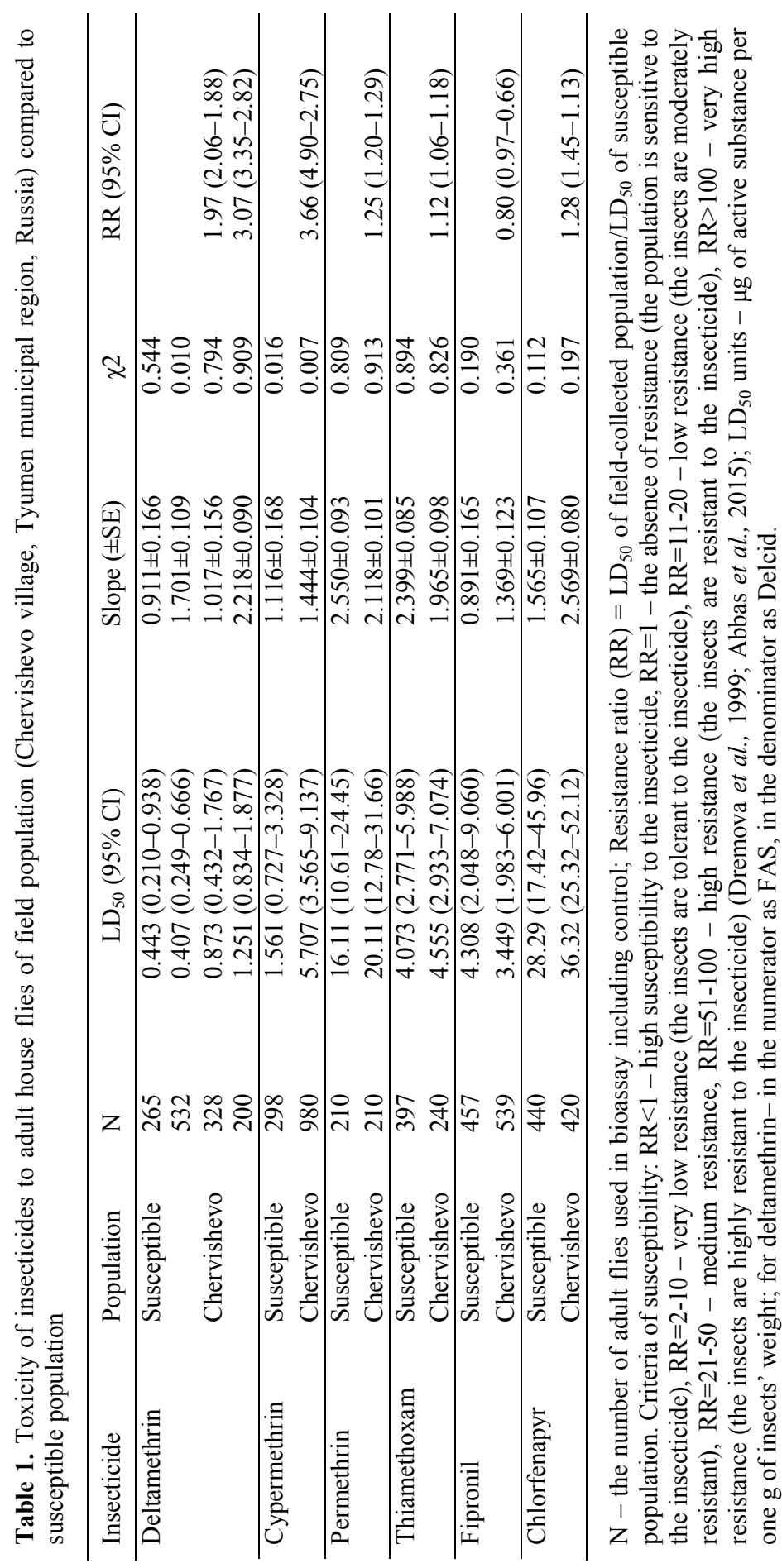


cide residues on glass surfaces (Marçon et al., 2003). In Florida dairy farms, population of flies resistant to pyrethroids have been also found: more than 20 -fold resistant to permethrin and 10-fold to the betacyfluthrin (Kaufman et al., 2010). In Pakistan, population of flies resistant to pyrethroids have been also found on dairy farms: resistance ratio (at $\mathrm{LC}_{50}$ ) 30.2270.02 for cypermethrin and 5.73-18.31 for deltamethrin (Khan et al., 2013).

In Russia, in the Tyumen region, an exceptionally high resistance to pyrethroids during their long-term use in pig and calf barns in Nizhnaya Tavda village was found in the local population of house flies, and a higher resistance was observed to the more effective preparations. In 1999, RR to Butox (deltamethrin 5\% EC) was 1600, Fastak (alpha-cypermethrin $10 \%$ EC) - 1000, Arrivo (cypermethrin $25 \%$ EC) - 800, Stomasanum (permethrin $20 \%$ EC) - 200, Baversan (fenvalerate EC) -50 , mixtures of malathion and cypermethrin - 200, permethrin with diazinon - 61 and chlorfenvinphos with alphamethrin - 45 (Pavlov et al., 2006).

The studied field house fly population did not reveal resistance to thiamethoxam $(\mathrm{RR}=1.12)$, despite the fact that neonicotinoid insecticides are quite common. Researchers from different countries noted the formation of resistance to neonicotinoids in natural populations of the house fly. For example, Kaufman et al. (2010) reported the emergence of tolerant and resistant to imidacloprid house fly populations on Florida State dairy farms. According to Khan et al. (2015), the flies collected in different areas of Pakistan had different resistance to thiamethoxam: RR (at LC50 values) ranged from 7.66 to 20.13 .

Another insecticide, to which the field population of flies caught by us was also susceptible was chlorfenapyr $(\mathrm{RR}=1.28)$. As can be seen from the results, chlorfenapyr is inferior to fipronil and pyrethroids in toxicity for flies of both labsusceptible and field populations. In the available literature, there is no information about the formation of house fly populations resistant to chlorfenapyr. This is probably due to the absence of chlorfenapyr containing preparations for combating flies, and its predominant use for plant protection.

Our results show a high susceptibility of the field population to fipronil ( RR = 0.80). In Russia insecticides containing fipronil are allowed in the form of gels and poisoned baits (for example, to control cockroaches), and therefore such preparations are not applied to control the fly populations. This is probably the reason why field populations of flies on farms retain susceptibility to fipronil. Given the high toxicity of fipronil for flies and a high susceptibility of the field population of flies to it, exploration and development of a suitable method of fipronil use to reduce the number of flies on livestock breeding complexes is considered promising. It is important to consider the world experience, indicating the possibility of forming resistance to fipronil in house flies after its intensive use (Kristensen et al., 2004; Abbas et al., 2016).

Overall, the results suggest that the population of $M$. domestica on the livestock farm in Chervishevo village, Tyumen municipal region, after many years of usage of pyrethroid insecticides to control flies, retained susceptibility to permethrin and acquired tolerance or very low resistance to deltamethrin and cypermethrin. It is necessary to restrict the use of pyrethroids to fly control. The monitoring of the susceptibility of field $M$. domestica populations to the conventional 
and new insecticides is important for more effective of houseflies control on livestock complexes.

From practical point of view, in order to prevent the development of resistance, it is important to use the rotation of insecticides with different modes of action, taking into account the level of susceptibility of the local population to the insecticides used. The rotation scheme can be as follows: organophosphates - neonicotinoids - carbamates - neonicotinoids (Roslavtseva, 2011). According to our results, the flies of field population are susceptible to pyrroles (fipronil) and pyrazoles (chlorfenapyr), therefore, the design of fiproniland chlorphenapyr-containing insecticidal formulations for flies control and their inclusion in a system of integrated pest management seems promising.

\section{REFERENCES}

Abbas, N., S. Ali Shad, \& M. Ismail, 2015. Resistance to conventional and new insecticides in house flies (Diptera: Muscidae) from poultry facilities in Punjab, Pakistan. Journal of Economic Entomology, 108, 826-833.

Abbas, N., M. Ijaz, S. A. Shad \& M. Binyameen, 2016. Assessment of resistance risk to fipronil and cross resistance to other insecticides in the Musca domestica L. (Diptera: Muscidae). Veterinary Parasitology, 223, 71-76.

Dremova, V. P., L. S. Putintseva \& P. E., Khodakov, 1999. Medical disinsection. Basic principles, means and methods. Vitar-Putived Publ., Ekaterinburg, Russia (RU).

Finney, D., 1971. A statistical treatment of the sigmoid response curve, Probitanalysis, $3^{\text {rd }}$ edn, Cambridge University Press, London.

Förster, M., S. Klimpel, H. Mehlhorn, K. Sievert, S, Messler \& K. Pfeffer, 2007. Pilot study on synanthropic flies (e.g.
Musca, Sarcophaga, Calliphora, Fannia, Lucilia, Stomoxys) as vectors of pathogenic microorganisms. Parasitology Research, 101, 243-246.

Kaufman, P. E., S. C. Nunez, R. S. Mann, C. J. Geden \& M. E. Scharf, 2010. Nicotinoid and pyrethroid insecticide resistance in houseflies (Diptera: Muscidae) collected from Florida dairies. Pest Management Science, 66, 290-294.

Khan, H. A., W. Akram \& S. A. Shad, 2013. Resistance to conventional insecticides in Pakistani populations of Musca domestica L. (Diptera: Muscidae): A potential ectoparasite of dairy animals. Ecotoxicology, 22, 522-527.

Khan, H. A., W.Akram, J. Iqbal \& U. NaeemUllah, 2015. Thiamethoxam resistance in the house fly, Musca domestica L.: Current status, resistance selection, crossresistance potential and possible biochemical mechanisms. PLoS One, 10, $\mathrm{e} 0125850$.

Kristensen, M., J. B. Jespersen \& M. Knorr, 2004. Cross-resistance potential of fipronil in Musca domestica. Pest Management Science, 60, 894-900.

Liu, N. \& Yue, X., 2000. Insecticide resistance and cross-resistance in the house fly (Diptera: Muscidae). Journal of Economic Entomology, 93, 1269-1275.

Marçon, P. C., G. D. Thomas, B. D. Siegfried, J. B. Campbell \& S. R. Skoda, 2003. Resistance status of house flies (Diptera: Muscidae) from southeastern Nebraska beef cattle feedlots to selected insecticides. Journal of Economic Entomology, 96, 1016-1020.

N'Guessan, R., P. Boko, A. Odjo, M. Akogbéto, A. Yates \& M. Rowland, 2007. Chlorfenapyr: A pyrrole insecticide for the control of pyrethroid or DDT resistant Anopheles gambiae (Diptera: Culicidae) mosquitoes. Acta Tropica, 102, 69-78.

Pavlov, S. D., R. P. Pavlova, \& S. M. Mavljutov, 2006. About resistance of insects of "gnus" complex and house fly to action of modern insecticides. In: Entomological re- 
search in North Asia. Proceedings of the VII Inter-regional meeting of entomologists of Siberia and the Far East (in the framework of the Siberian Zoological Conference)]. Novosibirsk, Russia. pp. 416-418.

Pavlov, S. D. \& R. P. Pavlova, 2005. Study of the effectiveness of insecticides and insect populations resistant to their action by dose contacting (guidelines). Tyumen: Tyumen State Agricultural Academy Publishing (RU).

Polyakova, Y. B., 1995. Biological indices and resistance to insecticides of house flies from areas with various chemical contamination. PhD thesis. Moscow, 22 p. (RU).

Romero, A., M. F. Potter \& K. F. Haynes, 2010. Evaluation of chlorfenapyr for control of the bed bug, Cimex lectularius L. Pest Management Science, 66, 12431248.

Roslavtseva, S. A., 2001. Investigation of the sensitivity of house flies populations in Moscow. RET-INFO, 2, 12 (RU).

Roslavtseva, S. A., 2011. Houseflies and control measures against these insects to nowadays. Pest Management, 1, 23-26 (RU).

Scott, J. G., C. A. Leichter, F. D. Rinkevich, S. A. Harris, C. Su, L.C. Aberegg, R. Moon, C. J. Geden, A. C. Gerry, D. B. Taylor, R. L. Byford, W. Watson, G. Johnson, D. Boxler \& L. Zurek, 2013. Insecticide resistance in house flies from the United States: Resistance levels and frequency of pyrethroid resistance alleles. Pesticide Biochemistry and Physiology, 107, 377-384.

Scott, J. G., W. C. Warren, L. W. Beukeboom, D. Bopp, A. G. Clark, S. D. Giers, M. Hediger, A. K. Jones, S. Kasai, C. A. Leichter, M. Li, R. P. Meisel, P. Minx, T. D.
Murphy, D. R. Nelson, W. R. Reid, F. D. Rinkevich, H. M. Robertson, T. B. Sackton, D. B. Sattelle, F. Thibaud-Nissen, C. Tomlinson, L. van de Zande, K. Walden, R. K. Wilson \& N. Liu, 2014. Genome of the house fly, Musca domestica L., a global vector of diseases with adaptations to a septic environment. Genome Biology, 15, 466.

Wang, Y .C., Y. C. Chang, H. L. Chuang, C. C. Chiu, K. S. Yeh, C. C. Chang, S. L. Hsuan, W. H. Lin \& T. H. Chen. 2011. Transmission of Salmonella between swine farms by the housefly (Musca domestica). Journal of Food Protection, 74, 1012-1016.

US EPA (United States Environmental Protection Agency), 2001. Fact Sheets on New Active Ingredients. Pesticide Fact Sheet: Chlorfenapyr. https://www3.epa.gov/pesticides/chem_search/reg_actions/registration /fs_PC-129093_01-Jan-01.pdf (05 January 2017, date last accessed).

Paper received 13.02.2017; accepted for publication 05.06.2017

\section{Correspondence:}

Dr. Silivanova Elena Anatolievna All-Russian Scientific Research Institute of Veterinary Entomology and Arachnology, 625041, 2 Institutskaya str., Tyumen, Russian Federation. tel./fax: 8-10-3452-62-57-08, +79058204116; e-mail: e.a.silivanova@utmn.ru 